\title{
Primary Thyroid Lymphoma
}

\author{
Manish Gupta, ${ }^{1}$ Ginni Datta, ${ }^{1}$ Naiya Rao, ${ }^{1}$ Eshita Dadwal ${ }^{1}$
}

\begin{abstract}
Introduction:
Lymphoma primarily arising from thyroid gland is very rare. Most patients give a history of previous Hashimoto's thyroiditis and hypothyroidism.

Case Report

We hereby report one such rare case, who presented with neck swelling and hoarseness. The fine needle aspiration cytology being inconclusive, the patient was taken up for near total thyroidectomy. The histopathology revealed it to be lymphoma, which was further confirmed on immunohistochemistry. The further whole body checkup showed it to be Stage IIE tumor. The patient received chemotherapy for residual mass in neck and is under follow-up for last one year with no recurrence.
\end{abstract}

$\underline{\text { ABSTRACT }}$

Discussion

The case is being presented here due to its rarity, diagnostic dilemma and to discuss the management protocol for same. Keywords:

Thyroid Neoplasms; Lymphoma; Autoimmune Diseases; Hashimoto Disease; Lymphoma, B-Cell

$\mathrm{P}$ rimary thyroid lymphoma is a rare tumor, accounting for $0.5 \%$ to $5 \%$ of all thyroid malignancies and $2.5 \%$ to $7 \%$ of all extranodal lymphomas in most series. ${ }^{1,2}$

Typically, it occurs in middle-aged to elderly women with a background of Hashimoto's thyroiditis. ${ }^{3}$ The relative risk of developing thyroid lymphoma in patients with Hashimoto's thyroiditis has been reported to be 40 to 80 times greater than in general populations ${ }^{4}$ and it takes 20 to 30 years to develop thyroid lymphoma after the onset of Hashimoto's thyroiditis. ${ }^{5}$

Almost all cases of thyroid lymphoma are nonHodgkins lymphoma (NHL) with B cell origin, but few thyroid $\mathrm{T}$ cell lymphomas have been described as anecdotal cases. ${ }^{6}$

Diffuse large B cell lymphoma (DLBCL), accounting for $>50 \%$ of cases and extranodal marginal zone B cell lymphoma of mucosa-associated lymphoid tissue (MALT) lymphoma (10-23\% cases) are its common subtypes. ${ }^{3,7}$

1 - Department of ENT, Maharishi Markandeshwar Institute of Medical Science and Research, MMU, Ambala, Haryana

\section{Corresponding author:}

Dr Manish Gupta

email: manishgupta1217@gmail.com

\section{Case Report}

A 45 year female presented to our out-patient department with complaint of progressive neck swelling for 10 years. There were complaints of difficulty in swallowing for 6 months, difficulty in breathing on lying down for 1 month and hoarseness for 10 days.

On examination the painless swelling was in lower anterior neck midline, $12 \mathrm{~cm} \mathrm{X} 7 \mathrm{~cm}$, moving on swallowing, firm to hard at places, involving both thyroid lobes and isthmus, with overlying skin normal. The indirect laryngoscopy revealed left true vocal cord palsy.

The thyroid function test suggested Hypothyroidism (Raised TSH and low T3, T4) while other routine blood investigations were within normal limits. There was high level of serum antithyroid microsomal antibodies. Fine needle aspiration cytology (FNAC) suggested thyroiditis. Patient was started on Thyroxine 50 microgram daily before breakfast. The chest $\mathrm{x}$-ray PA view showed tracheal deviation to right. The contrast enhanced computed tomogram (Fig. 1) was done, which showed a large $10 \mathrm{~cm} X 5.6 \mathrm{~cm}$ heterogeneously enhancing illdefined lobulated, solid lesion in left lobe, isthmus, with mild extension into right lobe of thyroid and retrosternal extension, till the origin of major vessels. There was 


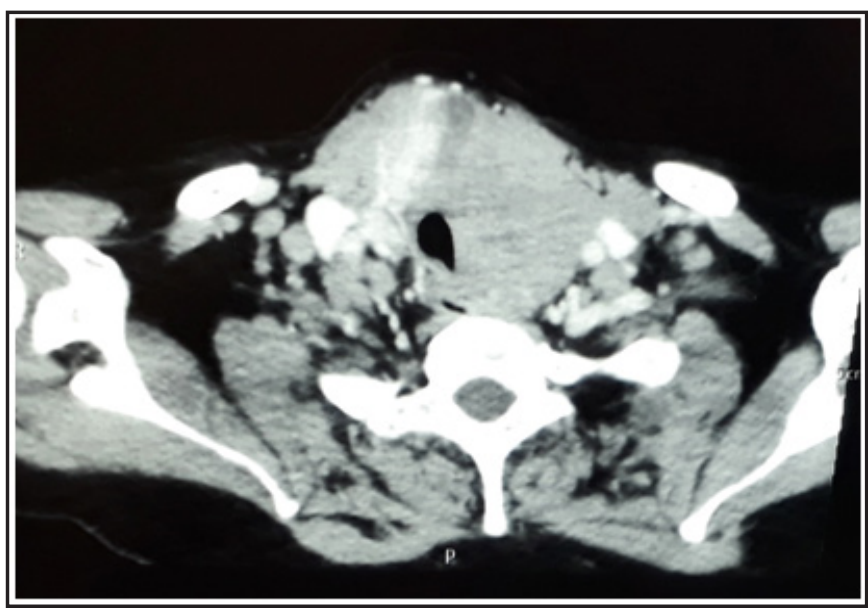

Fig. 1. The axial section, contrast enhanced computed tomogram of neck showing a large $10 \mathrm{~cm} X 5.6 \mathrm{~cm}$ heterogeneously enhancing, solid lesion in left lobe, isthmus, with mild extension into right lobe of thyroid.

no evidence of calcification or hemorrhage within the mass. Posteriorly, it was extenting till the prevertebral region and anterolaterally it reached up to subcutaneous tissue with involvement of the strap muscles bilaterally. Medially it involved left paraglottic space and laterally engulfing internal jugular vein and common carotid artery.

With high suspicion of malignancy but not proven by FNAC, the patient was taken up for near total thyroidectomy (Fig. 2) under general anesthesia. The firm to hard thyroid mass was seen adherent to strap muscles, engulfing left internal jugular vein and common carotid artery. The mass was separated from major vessels with use of blunt and sharp dissection, while strap muscles were sacrificed. Small uninvolved thyroid tissue along with right parathyroids were dissected away from the excised mass and preserved, over inferior thyroid pedicle. The left recurrent laryngeal nerve was also engulfed and could not be saved.

Histopathological evaluation showed, lymphocytic infiltration with destruction of thyroid follicles suggesting the diagnosis of lymphoma (Fig. 3). The large lymphoid cells possessed round, vesicular nuclei, distinct nucleoli and moderate amount of amphophilic cytoplasm (Fig. 4). The tumor cells infiltrated the thyroid follicles replacing the follicular epithelium. Focal areas of preserved thyroid tissue with features of lymphocytic

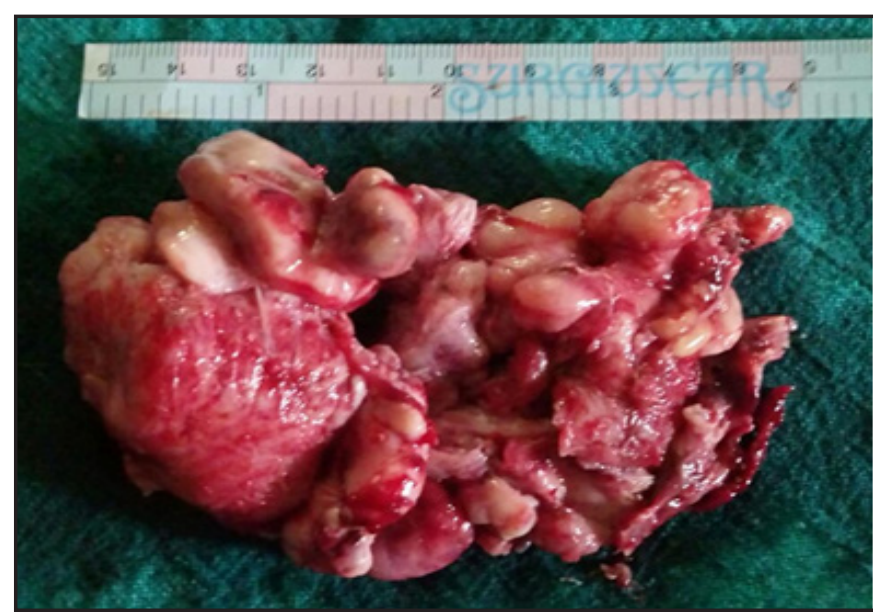

Fig. 2. The excised Near-total Thyroidectomy specimen showing, $10 \mathrm{~cm} \times 6 \mathrm{~cm}$ lobulated mass.

thyroiditis were seen. Immunohistochemistry showed tumor cells to be positive for CD20 (Fig. 5) and negative for CD3. Thus the diagnosis of diffuse large B-cell lymphoma in a background of Hashimoto's thyroiditis was made.

Post-operatively, the patient was worked up to rule out other organ involvement on both sides of diaphragm. All other investigations like chest X-ray PA view and abdomen ultrasound were within normal limits. Thus, it was staged IIE according to Ann Arbor staging system. The patient was started on chemotherapy (CHOP regime) with following drugs Vincristine, Adriamycin, Cyclophosphamide and Prednisolone, which the patient completed and has no residual or recurrence at primary site.

There is complete remission of disease with no evidence of any relapse or appearance of new lesion in one year follow-up.

\section{Discussion}

The thyroid lymphomas were classified as primary or secondary based on their clinical and pathologic features. Primary lymphomas of the thyroid were defined as the lymphomas with solely thyroid involvement or with the major tumor bulk in the thyroid at initial examination and others considered secondary. 


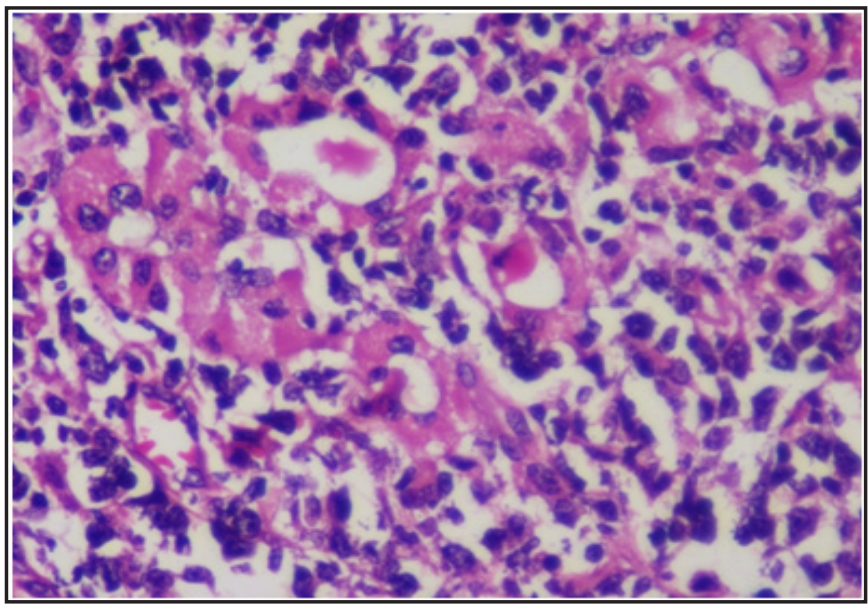

Fig. 3. Diffuse atypical lymphoid infiltrate arising in a background of Hashimoto's thyroiditis. Entrapped follicles show Hürthle cell change (H \& E, x400).

Primary thyroid lymphoma (PTL) typically develops in patients with a background of Hashimoto's thyroiditis. Because the normal thyroid gland has no native lymphoid tissue, thyroid lymphoma is thought to develop from lymphocytic tissue acquired during the course of chronic inflammation or an autoimmune process such as Hashimoto's thyroiditis and the prolonged presence of the stimuli leads to malignant transformation of the cells.1 The most prevalent form of PTL is diffuse large B-cell lymphoma, which is more invading than mucosaassociated lymphoid tissue lymphoma. ${ }^{7}$ Rarer subtypes of PTL include follicular, small lymphocytic, Hodgkin's lymphoma, T-cell, mantle cell and lymphoblastic lymphoma.

One study, discussed the role of Ebstein-Barr virus $(\mathrm{EBV})$ and found it to be causative in very small portion of thyroid lymphomas ( $4 \%$ to $9 \%$ of cases). ${ }^{8}$

The PTL mostly present as a swiftly growing thyroid mass. Typically, this mass has grown rapidly over 1 to 3 months, and may cause locally obstructive and infiltrative symptoms, such as dysphagia, dyspnea and hoarseness. ${ }^{9}$ Antibodies to one or more thyroid antigens like thyroperoxidase, thyroglobulin and $\mathrm{TSH}$ receptor are usually present with hypothyroidism.

Fine needle aspiration cytology (FNAC) is the initial procedure used for evaluation of a thyroid mass. However, the results of FNAC for the diagnosis of

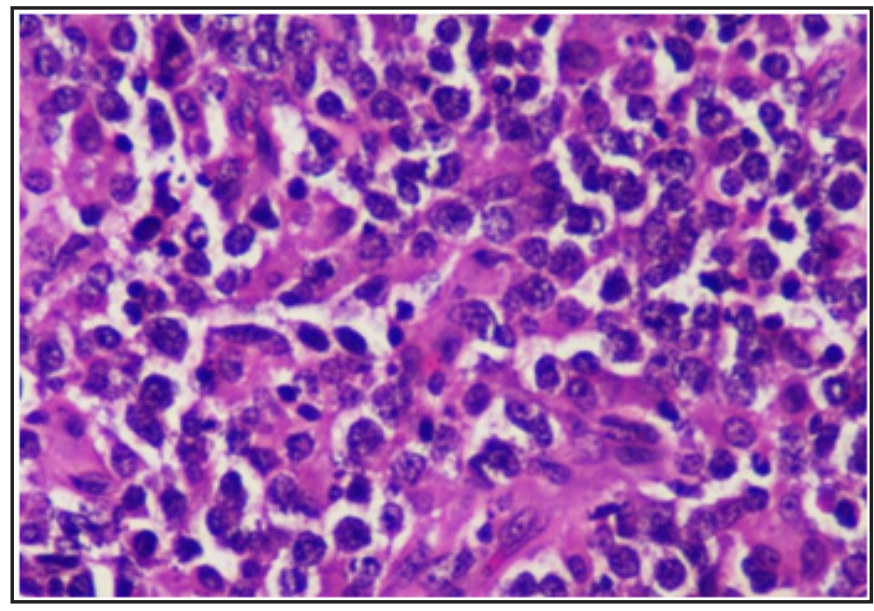

Fig. 4. Monomorphic population of medium to large sized atypical lymphoid cells with high $\mathrm{N}: \mathrm{C}$ ratio and scant cytoplasm infiltrating and replacing the thyroid parenchyma $(\mathrm{H} \& \mathrm{E}, \mathrm{x} 400)$.

thyroid lymphoma are inconsistent, and its diagnostic accuracy varies widely. ${ }^{10}$ Because, primary thyroid lymphoma develops in thyroid glands with pre-existing Hashimoto's thyroiditis, cytologic results of FNAC frequently reveal lymphocytes that are often erroneously diagnosed as the thyroiditis. Therefore, confirmatory procedures such as tissue biopsy or surgery are strongly recommended when primary thyroid lymphoma is suspected using FNAC. However, with recent advances in immunophenotypic analysis, the accuracy of FNAC has improved. This development in diagnosis of PTL is similar as for systemic lymphomas and has a reported definitiveness of $80-100 \%$ on FNAC. ${ }^{11}$

Ultrasonography is useful diagnostic modality for thyroid mass lesions. Although, nonspecific, but enhanced posterior echoes in lymphomas may help distinguish from other lesions and well defined borders separate lymphomatous from nonlymphomatous tissues. ${ }^{12}$ The positive predictive value of ultrasound was higher for the nodular type at $64.9 \%$ and the mixed type at $63.2 \%$ than for the diffuse type at $33.7 \%$, likely due to the latter's close resemblance to thyroiditis. ${ }^{12}$

To explain the prognosis and monitor for response of treatment, the clinical staging with the Ann Arbor staging system is used. ${ }^{13}$ Staging work-up included history taking and physical examination, laboratory evaluation, chest radiography, bone marrow aspiration 


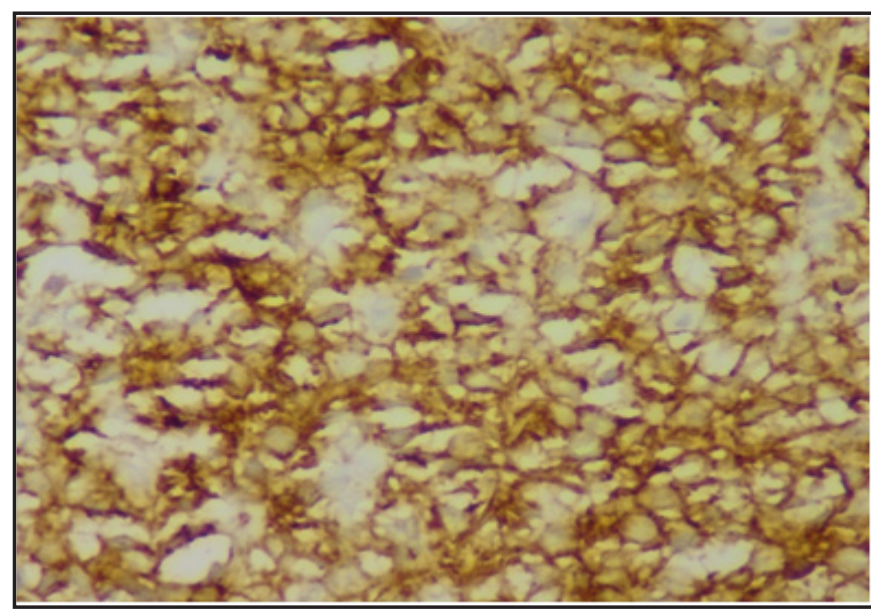

Fig. 5. Tumor cells show diffuse membranous positivity with CD20 (DAB, x400).

and biopsy, computed tomography of abdomen, pelvis, neck and chest. Stage IE - disease confined to the thyroid, Stage IIE - disease confined to the thyroid gland and the regional lymph nodes on the same side of the diaphragm, Stage IIIE - disease confined to the thyroid and lymph nodes on both sides of the diaphragm and/or spleen, Stage IV - Disseminated nodal and/or additional extranodal involvement.

Recently there has been interest in the utility of fluorodeoxyglucose (FDG) positron emission tomography (PET) scanning at initial diagnosis and in monitoring therapeutic response. Both the response to treatment and disease recurrence after treatment are detected earlier by FDG-PET compared to computed tomography. ${ }^{14}$ But its low diagnostic specificity, as FDG accumulation is seen in thyroid adenomas and carcinomas and relatively higher cost limits its use.

In one study, they found that $68 \%$ of patients with thyroid lymphoma had high titers of antithyroid (antithyroglobulin and antithyroperoxidase/ antimicrosomal) antibodies, and all patients showed histological evidence of Hashimoto's thyroiditis. ${ }^{9}$

The clinical prognostic factors in thyroid lymphoma are tumor size (greater than $10 \mathrm{~cm}$ ), advanced stage (greater than stage IE), presence of local obstructive symptoms, rapid tumor growth and mediastinal involvement. $^{3}$

The treatment of patients with thyroid lymphoma is controversial. ${ }^{15}$ It has been suggested that combined external radiation and adjuvant chemotherapy alone may achieve long term survival for patients with thyroid lymphoma. ${ }^{9}$ In another series, most of the cases had undergone surgery and received radiotherapy. ${ }^{8}$ They argued, that primary thyroid lymphomas arise in the setting of autoimmune thyroiditis, so surgical removal of gland would remove antigenic material prompting the lymphoid proliferation. A retrospective study on 26 patients with primary thyroid lymphoma proposed total thyroidectomy for localized MALT lymphomas and total thyroidectomy with single agent chemotherapy (Chlorambucil) for disseminated MALT lymphoma. ${ }^{16}$ For aggressive diffuse large B cell lymphoma, they recommended multidrug regimen chemotherapy and combination of chemotherapy plus radiotherapy for localized aggressive lymphoma. ${ }^{16}$

\section{References}

1. Isaacson PG. Lymphoma of the thyroid gland. Curr Top Pathol. 1997; 91:1-14

2. Kossev P, Livolsi V. Lymphoid lesions of the thyroid: review in light of the revised European- American lymphoma classification and upcoming World Health Organization classification. Thyroid 1999; 9:1273-80

3. Hwang YC, Kim TY, Kim WB, Shong YK, Yi KH, Shong M, Jo YS, Kim WS, Chung JH. Clinical characteristics of primary thyroid lymphoma in Koreans. Endocrine Journal 2009; 56:399-405

4. Holm LE, Blomgren H, Lowhagen T. Cancer risks in patients with chronic lymphocytic thyroiditis. N Enl J Med. 1985; $312: 601-4$

5. Pedersen RK, Pedersen NT. Primary non-Hodgkin's lymphoma of the thyroid gland: a population based study. Histopathology 1996 ; $28: 25-32$

6. Yamaguchi M, Ohno T, Kita K. T cell lymphoma of the thyroid gland. N Engl J Med. 1997; 336:1391-2

7. Stein S A, Wartofsky L. Primary thyroid lymphoma: A clinical review. J Clin Endocrinol Metab. 2013; 98:3131-8

8. Lam KY, Lo CY, Kwong DLW, Lee J, Srivastava G. Malignant lymphoma of the thyroid: A 30-year clinicopathologic experience and an evaluation of the presence of Epstein-Barr virus. Am J Clin Pathol. 1999; 112:263-70

9. Matsuzuka F, Miyauchi A, Katayama S, Narabayashi I, Ikeda H, Kuma K, Sugawara M. Clinical aspects of primary thyroid lymphoma: diagnosis and treatment based on our experience of 119 cases. Thyroid $1993 ; 3: 93-9$

10. Cha C, Chen H, Westra WH, Udelsman R. Primary thyroid lymphoma: can the diagnosis be made solely by fine- needle 
aspiration? Ann Surg Oncol. 2002; 9:298-302

11. Jeffers MD, Milton J, Herriot R, McKean M. Fine needle aspiration cytology in the investigation on non-Hodgkin's lymphoma. J Clin Pathol. 1998; 51:189-96

12. Ota H, Ito Y, Matsuzuka F, et al. Usefulness of ultrasonogrphy for diagnosis of malignant lymphoma of the thyroid. Thyroid 2006; 16:983-7

13. Carbone PP, Kaplan HS, Musshoff K, Smithers DW, Tubiana M. Report of the committee on Hodgkin's disease staging classification. Cancer Res. 1971; 31:1860-1
14. Basu S, Li G, Bural G, Alvi A. Fluorodeoxyglucose positron emission tomography (FDG-PET) and PET/ computed tomography imaging characteristics of thyroid lymphoma and their potential clinical utility. Acta Radiol. 2009; 50:201-4

15. Logue JP, Hale RJ, Stewart AL, et al. Primary malignant lymphoma of the thyroid: a clinicopathological analysis. Int $\mathrm{J}$ Radiat Oncol Biol Phys. 1992; 22:929-33

16. Thieblemont C, Mayer A, Dumontet C, Barbier Y, Callet-bauchu E, Felman P, Berger F, Ducottet X, Martin C, Salles G, Orgiazzi J, Coiffier B. Primary thyroid lymphoma is a heterogeneous disease. J Clin Endocrinol Metab. 2002; 87(1):105-11. 